\title{
Editorial
}

\section{Globalización y democracia}

En su informe anual del 2001, Amnistía Internacional (AI) denuncia el empobrecimiento y el aumento de las desigualdades en el actual orden mundial. El informe señala que la llamada globlalización se ha traducido, "en un enriquecimiento para algunos y en la ruina y desesperanza para la mayoría de los habitantes del planeta". En más de 180 países, el ingreso por habitante durante el 2000 fue inferior al de 1990, y "por lo menos 1300 millones de seres humanos intentan sobrevivir con menos de un dólar diario". Dada esta situación, Amnistía Internacional, que hasta hace poco se había dedicado principalmente a denunciar las violaciones a los derechos civiles y políticos, se pronuncia ahora por la necesidad de abordar la defensa y promoción de la totalidad de los derechos fundamentales de la persona humana, bajo el supuesto de que, hoy por hoy, la prioridad la tienen los derechos económicos, sociales y culturales.

En su informe sobre desarrollo humano de 1999, el PNUD señala que las desigualdades entre los ricos y los más pobres también han aumentado: una quinta parte de la población del mundo, viviendo en los países ricos, dispone del 86 por ciento del Producto Nacional Bruto, del 82 por ciento de los mercados de exportación, del 68 por ciento de la inversión extranjera directa, y del 74 por ciento de las líneas telefónicas. Otra quinta parte sólo dispone de alrededor de un 1 por ciento en cada sector. En 1999, las 200 personas más ricas del mundo acumulaban una riqueza igual a la renta del 45 por ciento de la población mundial, unos 2,400 millones de personas. Esto significa, obviamente, unas diferencias enor- 
mes de poder, que impiden que se pueda hablar seriamente de "igualdad de derechos" o de "democracia" a escala mundial. La mayor desigualdad de ingresos del mundo es la de América Latina. El 20 por ciento más pobre de la población ha visto reducirse su porcentaje de ingreso desde los años cincuenta, mucho antes de la crisis de la deuda externa. A comienzos de la década de los noventa, el 10 por ciento de los hogares latinoamericanos más ricos recibe el 40 por ciento del ingreso total, mientras que el 20 por ciento más pobre recibe menos del 4 por ciento. Una desigualdad cercana a la de América Latina es la que se da en la Rusia postcomunista (Cfr. L. De Sebastián, Neoliberalismo global. Apuntes críticos de la economía internacional, Madrid, 1997).

Tradicionalmente, el discurso político presuponía la existencia del estado nacional como marco de los procesos electorales sobre los que se sustentan y legitiman las llamadas democracias modernas. Los procesos globalizadores han erosionado radicalmente una de las bases del estado nacional, que era la idea de autoabastecimiento completo. Las redes financieras y comerciales trascienden las fronteras e imposibilitan cualquier ideal autárquico. Pero también el sueño de la soberanía estatal se está desmoronando. El crecimiento de las empresas multinacionales las convierte en unidades económicas mayores que muchos estados nacionales, dotadas de la capacidad de decidir, mediante sus políticas de inversión, sobre la suerte de millones de personas. La movilidad de capitales hace que sea muy difícil su control fiscal por parte de los estados, que tienen que ir transfiriendo los impuestos hacia el trabajo o hacia el consumo de sus propios ciudadanos. Además, los ciudadanos tienen que esperar al día de las elecciones para "castigar" las decisiones que consideren equivocadas de sus gobiemos. Los capitales, en cambio, pueden reaccionar inmediatamente a las decisiones gubernamentales que no sean de su agrado, retirándose a otros países o amenazando con hacerlo.

El debilitamiento de los viejos modos de decisión no significa que nadie decida. Otros son los que deciden. En el interior de los estados, las "elecciones democráticas" se limitan cada vez más a la elección entre dos élites de políticos profesionales, muy parecidos entre sí, y vinculados en todos los casos a los grandes capitales (Cfr. W. I. Robertson, "Nueve tesis sobre nuestra época", en Seminario Zubiri-Ellacuria, Mundialización y liberación, Managua, 1996, pp. 52-54.). Pero las grandes decisiones económicas trascienden el poder de los estados, y se toman en foros internacionales. Y estos foros, no son precisamente democráticos. El "Grupo de los Siete", posiblemente la organización con más relevancia sobre la economía mundial, es, como su nombre lo indica, un club reservado a una élite. El Fondo Monetario Internacional y el Banco Mundial, por su parte, se han apartado de sus fines fundacionales, convirtiéndose en un instrumento de la política económica de los países ricos, pues son éstos los que controlan su funcionamiento mediante un sistema de cuotas. Incluso las transferencias netas van en dirección contraria a la prevista; de los países pobres al Fondo Monetario y al Banco Mundial. No es extraño que los países ricos prefieran estas instituciones

\section{8}

Realidad 81, 2001 
frente a los organismos sociales y económicos de las Naciones Unidas, regidos por criterios más democráticos. Sin embargo, en las Naciones Unidas hay también mecanismos, como el derecho de veto, que garantiza el dominio de las naciones más poderosas, representantes de una muy pequeña parte de la humanidad.

En definitiva, cuando más poderosos son los organismos internacionales, menos democráticamente funcionan. De este modo, nos encontramos con la paradoja de que las instituciones que verdaderamente influyen en el mundo no son democráticas, y esta falta de democracia redunda a favor de los países ricos, muchos de los cuales suelen presentarse a sí mismos como ejemplos de democracia para el mundo entero (Cfr. A. González, "Orden mundial y liberación”, Estudios Centroamericanos (ECA), No. 549, 1994). El ejercicio del poder siempre requiere violencia o coerción, abierta o encubierta. Mucho más cuando el poder no es democrático y se ejerce sobre un mundo atravesado por la pobreza y la desigualdad. De hecho, los conflictos militares no han desaparecido con la caída del bloque soviético: mientras unos conflictos se han calmado, otros han surgido. Los Estados Unidos, con su superioridad militar incuestionada, se ha convertido en el policía que vigila la seguridad del nuevo orden mundial (F. Houtard, "Las alternativas creíbles del capitalismo mundializado", Pasos, No. 30, pp. 1-6, San José, Costa Rica, 2000).

Son estos datos y consideraciones los que revelan la verdad de la actual globalización o mundialización de las relaciones humanas: en lugar de un mundo capitalista sin dilemas, realizándose de forma cada vez más perfecta, visto como si fuera el clímax de la historia, nos encontramos en un mundo capitalista difícil, mucho menos interdependiente e integrado que problemático y contradictorio (Cfr. O. Ianni, La sociedad global, Siglo XXI, México, 1998, pp. 121122). En el mismo proceso de globalización se desarrollan la interdependencia y la integración y se promueven la desigualdad y la contradicción; y la democracia se desarrolla muy poco. La sociedad global se muestra así como una estructura mundial de enajenación.

Para algunos esta globalización tiene que ser aceptada como inevitable e irreversible. Desde el discurso dominante se ha anunciado el fin de la historia. El trayecto cubierto por los países ricos representaría el curso que tiene que ser recorrido inexorablemente por las demás sociedades del planeta; la humanidad habría llegado al agotamiento de las ideologías, al ocaso de la utopía, al lin de las alternativas y opciones. Hay un solo modelo (el individualismo competitivo de las sociedades capitalistas liberales) compatible con las exigencias cconómicas y tecnológicas de las sociedades industrializadas capitalistas. Y desde este modelo la ideología dominante proclama la necesidad de que los países subdesarrollados realicen profundas mutaciones culturales, cuyos patrones éticos y culturales se consideran obstáculo para el "desarrollo" que hoy se plantea. Se trata de las transformaciones que pernitirían a estas sociedades "entrar a la historia", alcanzando así a las ricas sociedades industrializadas.

Globalización y democracia 
Ciertamente la globalización es un hecho, pero su actual configuración y tendencia no es una necesidad o un destino inexorable de la humanidad, sino una opción deliberada, en función del predominio de los países ricos y del beneficio de sus empresas y del bienestar de sus ciudadanos. Ha sido la política, no la tecnología, lo que ha determinado la extensión, la profundidad y la configuración de la actual integración económica internacional (M. Wolff, "'WWill the NationState Survive Globalization?", Foreign Affairs, enero-febrero, 2001, p. 18). Y esta globalización no ha cumplido sus pretensiones y promesas en cuanto a un desarrollo más o menos integrado e integrador, universal e igualitario de las economías, las sociedades, las culturas, las regiones, naciones y Estados del planeta.

De cara a esta situación, I. Ellacuría afirmaba que "todavía no se ha llegado al estadio histórico en el cual la libertad de unos pocos no esté fundada en la negación de la libertad de muchos [...] La razón última está en que la libertad de todos para todo no se logra por la vía de la liberalización, sino por la vía de la liberación. La liberalización es la vía de los pocos fuertes, que están más preparados para aprovecharse de la supuesta igualdad de oportunidades. La liberación es el camino de las mayorías, que sólo accederán a la verdadera libertad cuando se liberen de un mundo de opresiones y cuando se den las condiciones reales para que todos puedan ejercitar su libertad" (I. Ellacuría, "Utopía y profetismo", Revista Latinoamericana de Teología, No. 17, 1989, p. 162). Para Ellacuría, la libertad debería verse desde su realización histórica en las mayorías pobres dentro de cada país y de los pueblos oprimidos en el conjunto del mundo. Es la humanidad la que debe ser libre y no unos cuantos privilegiados de la humanidad, sean individuos, clases sociales o naciones.

Este ideal utópico de una plena libertad para toda la humanidad sólo puede ser posible por la puesta en marcha de un proceso histórico de liberación. La transformación de la sociedad global en beneficio de las mayorías populares no es algo que vaya a suceder por sí mismo, en función de las "leyes inmanentes de la historia", o de la actividad de algún macrosujeto o entidad abstracta (espíritu, naturaleza, materia) que actúa por encima o detrás de las acciones humanas. En la visión ellacuriana de la historia (Cfr. I. Ellacuría, Filosofía de la realidad histórica, UCA Editores, San Salvador, pp. 491-6(02), las estructuras históricas no se transtorman por sí solas como suponen los modelos cstructuralistas, mecanicistas o cibernéticos; no tienen en sí mismas un fin predetenninado hacia donde transformarse; ni muchos menos están orientadas per se a transformarse hacia una meta liberadora y humanizadora. Este cambio supone la activación de luerzas sociales que provoquen conscientemente, dentro del marco de posibilidades históricas of recido en cada situación, el paso de una forma estructural a otra. Por ello es importante indagar sobre las posibilidades rcales que las estructuras actuales del mundo olrecen para la liberación. 